\title{
LOW BACK PAIN- THE METABOLIC DISEASE
}

\author{
Shekhar Singal', Hakam Singh², Pankaj Kumar ${ }^{3}$
}

${ }_{1}^{1}$ Assistant Professor, Department of Orthopaedics, Dayanand Medical College and Hospital, Ludhiana, Punjab, India.

2Senior Resident, Department of Orthopaedics, Dayanand Medical College and Hospital, Ludhiana, Punjab, India.

${ }^{3}$ Associate Professor, Department of Psychiatry, Dayanand Medical College and Hospital, Ludhiana, Punjab, India.

\section{ABSTRACT}

\section{BACKGROUND}

Low backache can be defined as acute or chronic ache localized to the anatomic area below the posterior ribs and above the lower margin of buttocks. Patients with complex back pain have increased risk of underlying medical conditions and need further workup. The causes of LBP can be broadly classified into mechanical, metabolic, inflammatory, neoplastic or traumatic. The present study was designed to study the metabolic factors associated with low back ache.

\section{MATERIALS AND METHODS}

This is a descriptive study done in the department of orthopedics at Dayanand Medical College \&Hospital, Ludhiana, from $1 / 02 / 2014$ to $1 / 06 / 2015$. Patients with low back ache persisting for $>6$ weeks, not responding to conservative treatment, without any neurological deficit, irrespective of sex type, were included in the study. Patients below the age of 18 years, or having neoplasm were excluded from the study. Thorough history was taken from the patients and attendants. The patients underwent physical and clinical examination and investigations like TLC, ESR, Calcium, Phosphorous, Alkaline Phosphatase, Creatine, SGOT, SGPT and Vitamin D levels and X rays of the lumbosacral spine were done for every patient. Osteoporosis was graded on the X-rays according to Jikei University Classification. If required by the clinician, MRI or bone scan was done to arrive at the final diagnosis.

\section{RESULTS}

Out of the 32 patients in the study, 14 had metabolic bone disease. Mean age of the patients with metabolic bone disease was 52.9 years. Out of 14 patients with metabolic bone disease, 3 were males and 11 were females; and 9 (28.13\%) showed decreased vitamin D levels in their serum. There was a significant difference in sun exposure between the patients with vitamin D deficiency and rest of the patients. Low calcium intake and hypovitaminosis D were directly related to low back pain.

\section{CONCLUSION}

This study looked into various metabolic factors contributing to low back pain in Indian population. There is high prevalence of metabolic disease in elderly females with chronic backache, which should be properly screened, and the subjects should be adequately supplemented with vitamin $\mathrm{D}$ and calcium.

\section{KEY WORDS}

Low Back Pain, Metabolic, Vitamin D, Calcium

HOW TO CITE THIS ARTICLE: Singal S, Singh H, Kumar P. Low back pain- the metabolic disease. J. Evolution Med. Dent. Sci. 2019;8(11):774-776, DOI: $10.14260 /$ jemds/2019/170

\section{BACKGROUND}

Low backache can be defined as acute or chronic ache localized to the anatomic area below the posterior ribs and above the lower margin of buttocks.(1) Low back pain is highly prevalent and a major health burden in India as well as globally.(2-3) Low back pain can be classified as Simple or Complex. Majority of the patients have simple back pain, where there are no risk factors or signs of underlying pathology. Patients with complex back pain have increased risk of underlying medical conditions and need further workup with laboratory tests and plain radiographs. Risk factors for complex back pain include age over 50 years, history of cancer or intravenous drug use, signs or symptoms of systemic disease and sciatica or neurologic deficit on examination.

'Financial or Other Competing Interest': None.

Submission 02-02-2019, Peer Review 03-03-2019,

Acceptance 06-03-2019, Published 18-03-2019.

Corresponding Author:

Dr. Pankaj Kumar,

1348/35, St. No. 03, Rishi Nagar Extension,

Habowal Khurd, Ludhiana-141001, Punjab, India.

E-mail: drpkspsy@gmail.com

DOI: $10.14260 /$ jemds $/ 2019 / 170$
Most patients with low back pain cannot be given a definitive diagnosis owing to loose association among symptoms, physical examination, imaging tests and anatomic findings. Therefore, LBP should be considered as a disorder, rarely attributable to a specific disease or a pathologic reason. The causes of LBP can be broadly classified into mechanical, metabolic, inflammatory, neoplastic or traumatic. Considering the high prevalence of metabolic disorders like osteoporosis, osteomalacia, hyperparathyroidism, hyperthyroidism in Indian population, the present study was designed to study the metabolic factors associated with low back ache.

\section{MATERIALS AND METHODS}

This is a descriptive study done in the department of orthopedics at Dayanand Medical College \&Hospital, Ludhiana, from $1 / 02 / 2014$ to $1 / 06 / 2015$. All the patients with low back ache persisting for $>6$ weeks, not responding to conservative treatment, without any neurological deficit irrespective of sex type were included in the study. Patients below the age of 18 years, or having neoplasm were excluded from the study.

Thorough history was taken from the patients and attendants, particularly stressing upon the dietary habits, sun exposure, alcohol intake and smoking. 
The patients underwent physical and clinical examination to assess the nutritional status. Investigations like TLC, ESR, Serum Calcium, Phosphorous, Alkaline phosphatase, Creatine, SGOT, SGPT and Vitamin $\mathrm{D}$ levels and $\mathrm{X}$ rays of the Lumbosacral spine were done for every patient. Osteoporosis was graded on the X-Rays according to Jikei University Classification. Then if required by the clinician, MRI or bone scan was done to arrive at the final diagnosis.

\section{Ethics}

The procedures followed were in accordance with the ethical standards of the responsible committee on human experimentation and with the Helsinki Declaration of 1975 that was revised in 2000. No experiments were done on animals.

\section{Statistics}

Out of the 32 patients in the study, 14 had metabolic bone disease. Mean age of the patients with metabolic bone disease was 52.9 years. Out of 14 patients with metabolic bone disease, 3 were males and 11 females; and 9 (28.13\%) showed decreased vitamin D levels in their serum. There was a significant difference in sun exposure between the patients with vitamin D deficiency and rest of the patients. Low Calcium intake and hypovitaminosis D were directly related to Low Back Pain. Alcohol intake and diet (vegetarian or nonvegetarian) didn't seem to affect low back ache.

\section{RESULTS}

To our knowledge this is one of the first studies of its type to look into various metabolic factors together contributing to Low back pain in Indian population. Whereas the previous studies have concentrated on single metabolic factor, mainly Vitamin D in causing Low back ache. There is high prevalence of metabolic disease in elderly females with chronic backache, which should be properly screened for and the subjects should be adequately supplemented with Vitamin D and Calcium. This study may prove to be of clinical value in determining protocols for management of chronic low back ache.

\begin{tabular}{|c|c|c|c|}
\hline Age & Total No. & +ve cases & \% Age +ve Cases \\
\hline$<=50$ & 16 & 4 & 25 \\
\hline$>50$ & 16 & 10 & 62.50 \\
\hline Z Value & 2.14 & p Value & $<0.05$ \\
\hline \multicolumn{4}{|c|}{ Table 1. Age Related Positive Cases } \\
\hline
\end{tabular}

\begin{tabular}{|c|c|c|c|}
\hline Sex & Total No. & +ve Cases & \% Age +ve Cases \\
\hline Male & 14 & 3 & 21.43 \\
\hline Female & 18 & 11 & 61.11 \\
\hline Z-value & 2.25 & p value & $<0.05$ \\
\hline \multicolumn{4}{|c|}{ Table 2. Sex Related Positive Cases } \\
\hline
\end{tabular}

\begin{tabular}{|c|c|c|c|c|}
\hline Parameters & $\begin{array}{c}\text { Positive } \\
\text { No. }\end{array}$ & $\begin{array}{c}\text { Positive } \\
\text { \% Age }\end{array}$ & $\begin{array}{c}\text { Negative } \\
\text { No. }\end{array}$ & $\begin{array}{c}\text { Negative } \\
\text { \% Age }\end{array}$ \\
\hline Low TSH & 2 & 6.25 & 30 & 93.75 \\
\hline Low S. Ca & 7 & 21.88 & 25 & 78.13 \\
\hline Low Vitamin D & 9 & 28.13 & 23 & 71.88 \\
\hline Osteoporosis & 10 & 31.25 & 22 & 68.75 \\
\hline Combined & 14 & 43.75 & 18 & 56.25 \\
\hline Table 3. Positive Cases Based on Different Parameters \\
\hline
\end{tabular}

\section{DISCUSSION}

There is high prevalence of Low back Pain in the population. Studies in the developed nations have shown it's point prevalence was $6.8 \%$ in North America, $13.7 \%$ in Denmark, $12 \%$ in Sweden.(4) Such studies in developing nations have reported its incidence much higher.

The results of the present study showed that with increasing age the role of various metabolic factors contributing to low back ache increases. $71 \%$ of the patients having low back ache in the study were $>50$ years of age. Similarly, a high preponderance of metabolic disease was noted in females. So, the elderly females with chronic low back ache should be screened for underlying metabolic disease.

In our study $71.85 \%$ of the subjects with low back pain, had poor intake of Vitamin D. So, it becomes clearly evident that Vitamin D intake is directly related to incidence of Low back pain. Similar results were found in study by Al Faraj S et al, (5) where they found $83 \%$ patients having low intake of Vitamin D; and study by Ghai et al(6) found $66 \%$ patients with Chronic Low Backache to have hypovitaminosis D.

$28 \%$ of the subjects were found to have hypovitaminosis $D$, all of these subjects on further screening showed underlying metabolic disease. This is in stark contrast to studies by Thornbey A et al(7) and Ajay Panwar et al(8) who concluded that marginal to moderate form of Vitamin D deficiency may not be pathogenetically associated with Low Back Pain. This difference could be because, all the subjects with hypovitaminosis D had an underlying metabolic disease. So, it is being hypothesized that Vitamin D deficiency with underlying metabolic disease is possibly having a causal association with low back ache, and its correction may have a role in treating the same.

Age and gender-based prevalence of hypovitaminosis D showed no significant difference, meaning similar incidence in younger individuals. This could be explained on the basis that most of the younger individuals in our study had sedentary life style and had little exposure to sun.

Lower mean sunlight exposure was found in subjects with hypovitaminosis D. 57\% subjects having metabolic disease had little sun exposure. This is in accordance to study by Mellisa K Thomas et al, (9) which established a clear-cut relationship between UV light exposure and vitamin D levels measured in winter and summer months. Similar results were observed in study by Ajay Panwar et al.(8)

Only 21\% subjects showed lower Serum calcium levels, and all were females in the elderly age group. So it is concluded that elderly females with chronic low back pain should not only be supplemented with Vitamin D, but adequate supplementation of calcium is required along with. Same was concluded in the study by Torrent de la Jara G et al,(10) where patients responded to the treatment with intramuscular cholecalciferol and oral calcium.

Hyperthyroidism has been thought to be a risk factor for osteoporosis. Hyperthyroid patients show generalized reduction of bone mass in axial skeleton contributing to low back pain. Same has been proved in study by Jodar E et al.(11) But due to small sample size of hyperthyroid patients in our study, nothing significant could be concluded.

We found no relation between alcohol intake, its quantity as well as frequency having any statistical significance in causing low back pain. Similar no difference was observed 
with regards to dietary habits whether vegetarian or nonvegetarian. This is against the common myth of higher prevalence of metabolic disease in vegetarians.

\section{CONCLUSION}

This study looked into various metabolic factors contributing to low back pain in Indian population. There is high prevalence of metabolic disease in elderly females with chronic backache, which should be properly screened, and the subjects should be adequately supplemented with vitamin $\mathrm{D}$ and calcium.

\section{REFERENCES}

[1] Rozenberg S. Chronic low back pain: definition and treatment. Rev Prat 2008;58(3):265-72.

[2] Volinn E. The epidemiology of low back pain in the rest of the world. A review of surveys in low- and middle-income countries. Spine 1997;22(15):1747-54.

[3] Hoy D, March L, Brooks P, et al. The global burden of low back pain: estimates from the Global Burden of Disease 2010 study. Ann Rheum Dis 2014;73(6):96874.

[4] Loney PL, Stratford PW. The prevalence of low back pain in adults: a methodological review of the literature. Phys Ther 1999;79(4):384-96.

[5] Al Faraj S, Al Mutairi K. Vitamin D deficiency and chronic low back pain in Saudi Arabia. Spine 2003;28(2):177-9.
[6] Ghai B, Bansal D, Kanukula R, et al. Vitamin D supplementation in patients with chronic low back pain: an open label, single arm clinical trial. Pain Phys 2017;20(1):E99-e105.

[7] Thorneby A, Nordeman LM, Johanson EH. No association between level of vitamin $\mathrm{D}$ and chronic low back pain in Swedish primary care: a crosssectional case-control study. Scand J Prim Health Care 2016;34(2):196-204.

[8] Panwar A, Valupadas C, Veeramalla C, et al. Prevalence of vitamin $\mathrm{D}$ deficiency in chronic and subacute low back pain patients in India: a triple-arm controlled study. J Clinical Rheumatology 2018;37(5):1367-74.

[9] Thomas MK, Lloyd-Jones DM, Thadhani RI, et al. Hypovitaminosis D in medical inpatients. The New England Journal of Medicine 1998;338(12):777-83.

[10] De Torrente de la Jara G, Pecoud A, Favrat B. Female asylum seekers with musculoskeletal pain: the importance of diagnosis and treatment of hypovitaminosis D. BMC Fam Pract 2006; 7:4.

[11] Jodar E, Munoz-Torres M, Escobar-Jimenez F, et al. Bone loss in hyperthyroid patients and in former hyperthyroid patients controlled on medical therapy: influence of aetiology and menopause. Clin Endocrinol (Oxf) 1997;47(3):279-85. 